Physical Geography; Cartography; Geographic Information Systems \& Spatial Planing

\title{
WRF SIMULATION OF TORNADO DEVELOPMENT: A CASE STUDY IN
}

TUZLA, ISTANBUL

DOI: http://dx.doi.org/10.18509/GBP.2015.22

UDC: $551.515 .3: 004.94(560)$

\section{Kübra Ağaç \\ Nilcan Akataş \\ Assoc. Prof. Dr. Ali Deniz}

Istanbul Technical University, Faculty of Aeronautics and Astronautics, Department of Meteorological Engineering, Maslak, İstanbul, Turkey

\begin{abstract}
A short lived tornado occurred in Tuzla, Istanbul on June 19, 2014. The tornado passed over the Marmara Sea by hitting Pendik and Tuzla and then moved forward to Kocaeli which is located in easternmost end of Marmara Sea. It damaged to ships and houses along the Marmara Sea shore. Many trees and lampposts fell over during the tornado. It was an extraordinary event for this region because Marmara is an inland sea. Thus, this rare tornado case was chosen for the study, and its development was simulated by using WRF mesoscale numerical weather prediction model, with different initial conditions. The simulations were compared with synoptic maps and radar and satellite images. In addition, observation data (wind speed, temperature, pressure and precipitation) which belongs to Pendik and Kocaeli observation stations of Turkish State Meteorological Service was used in order to determine the weather conditions for event day.
\end{abstract}

Keywords: Tornado, Turkey, İstanbul, WRF, Mesoscale modelling.

\section{INTRODUCTION}

Tornado is a whirling and moving column of air with high wind speeds connected with both surface and cumulonimbus clouds. Tornadoes are one of the nature's most violent phenomena which are connected to the severe storms. Tornadoes can be different size and shapes but they are in the form of visible condensation funnel with end touching ground. Tornadoes can be classified as their damage degree. For classification Fujita and TORRO scales can be used. Fujita Scale is changed from 0 to 7 according to tornado damage [1]. TORRO Scale (The Tornado and Storm Research Organization) levels change from 0 to 10 according to wind speed of system and damage level.

There are many studies about tornadoes' synoptic analyzes and numerical predictions. In Greece, there was a study about tornado development with WRF-ARW simulation and the results were compared with the observed station data [2]. Also over India there was another tornado case study was analyzed and again WRF-ARW was used for simulation and then the synoptic upper level and low level charts were investigated, the study of tornado development was also supported with satellite images [3]. At Bangladesh, the tornado's synoptic and environmental features were studied and its impacts were discussed [4].

For this paper, our aim was to simulate tornado case which was occurred June 19, 2014 in Tuzla. WRF-ARW model was run with different parameters to see the upper level wind speeds, wind directions and precipitation. Then, with the synoptic upper level and low level charts, the formation and dissipation phases of a tornado were analyzed. According to the damage degree, the tornado was classified to the Fujita and TORRO scale. Satellite 
and radar images put forward the cloudiness and precipitation situation. Measured meteorological data (pressure, temperature, wind speed and direction) of the two automatic observation stations were analyzed and they were compared to the simulations.

\section{CASE DESCRIPTION}

Tornado was observed in Tuzla, Istanbul (Lat: $40.81^{\circ} \mathrm{N}$, Lon: $29.30^{\circ} \mathrm{E}$ ) on June 19, 2014 approximately at 15:30 UTC. The system developed nearly between 15:00 and 16:00 UTC and it caused significant damages to ships, houses, lampposts and trees along the Marmara Sea shore. Based of the damages it could be characterized as an F2 (Fujita Scale) and T2 (TORRO scale). The tornado followed the path from Marmara Sea to Black Sea.

\section{METHODOLOGY}

The occurrence and development of tornado was simulated by using mesoscale weather prediction model WRF and model outputs were compared to synoptic maps, radar and satellite images. After the comparison pressure, temperature, wind speed and wind direction data taken from Turkish State Meteorological Service were analyzed where tornado passed along.

The WRF model has two dynamical core variants named nonhydrostatic mesoscale (NMM) and advance research (ARW). In this study, WRF-ARW (version 3.4.1) was run with two nested domains; $10 \mathrm{~km}$ grid resolution for coarser domain including the Eastern part of Europe, Turkey located between Aegean Sea, Black Sea and Mediterranean Sea (Fig.1), and with $3.3 \mathrm{~km}$ grid resolution for the inner domain focusing on the Eastern part of Turkey. WRF simulations obtained with two different physics options. As surface scheme, for the first simulation, Kain-Fritsch cumulus and Monin-Obukhov similarity theory surface physics were chosen. For the second simulation, Grell-Devenyi Ensemble cumulus and GFS Monin-Obukhov similarity theory surface physics were chosen. Both for these two run, the rest physics were taken as default. Initial and boundary conditions for atmospheric simulations with the WRF-ARW model were generated from NCEP (National Centers for Environmental Prediction) Final Operational Model Global Tropospheric Analyses data set with 6-hour interval. The data are archived at $1^{\circ} \mathrm{x} 1^{\circ}$ horizontal resolution on 26 pressure levels. 1-hour simulation results cover the period between June 17-June 21, 2014 in order to see formation to dissipation phases of tornado.

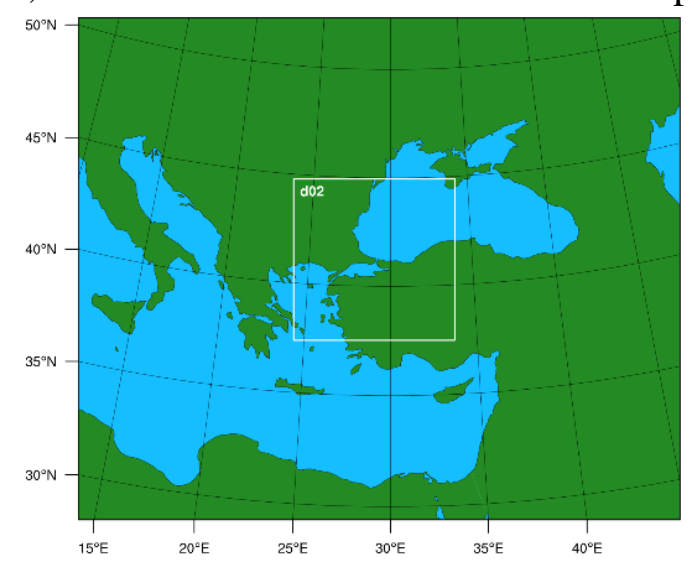

Figure 1: WRF-ARW domain configuration. 
The synoptic analysis for tornado day (June 19, 2014) indicated that a cyclonic circulation moving to the east passing over where tornado hit. The upper analysis (500 mb) showed that there was a trough western part of Tuzla at 12:00UTC (Fig. 2a) and then the trough had been moving to the eastern part of the area at 18:00UTC (Fig. 2b).
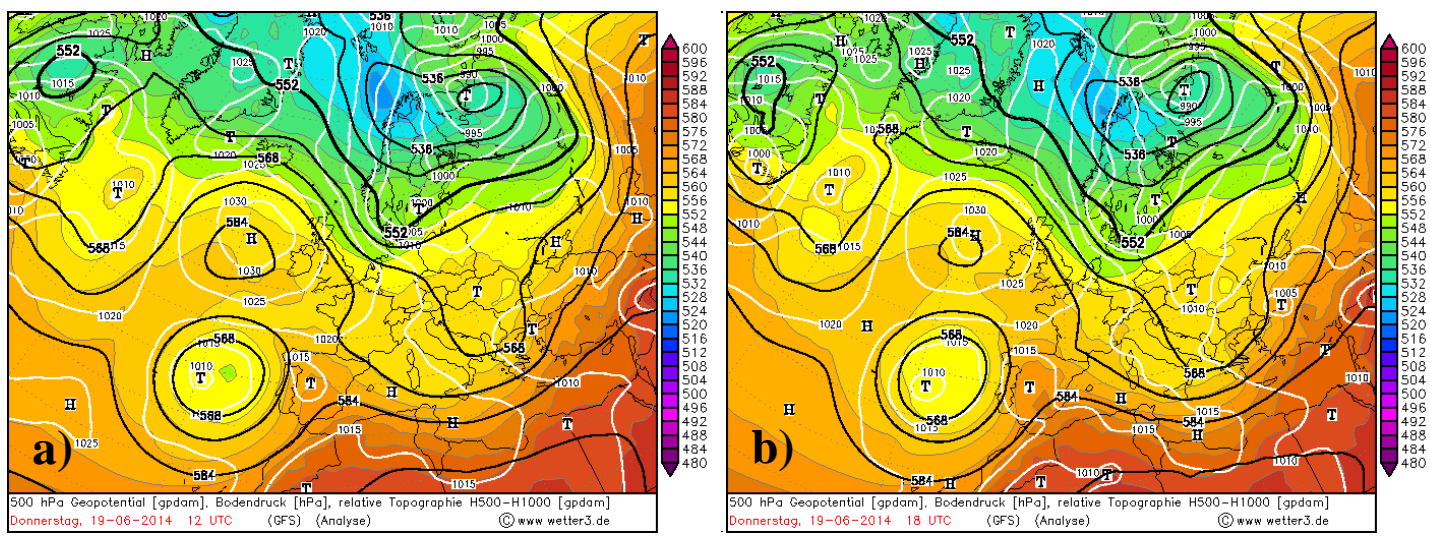

Figure 2: $500 \mathrm{mb}$ geopotential (gpdam) and pressure (mb) at a)12:00UTC; b)18:00UTC

In the lower analysis charts (850 mb frontal zone and temperature maps), at 12:00UTC there was a cold front at the western part of the Tuzla (Fig. 3a) then front had been moving to the eastern part of the area, at 18:00UTC there was a cold front over where tornado hit. The $850 \mathrm{mb}$ temperature changes between 12:00 (Fig. 3c) and 18:00UTC (Fig. 3d)
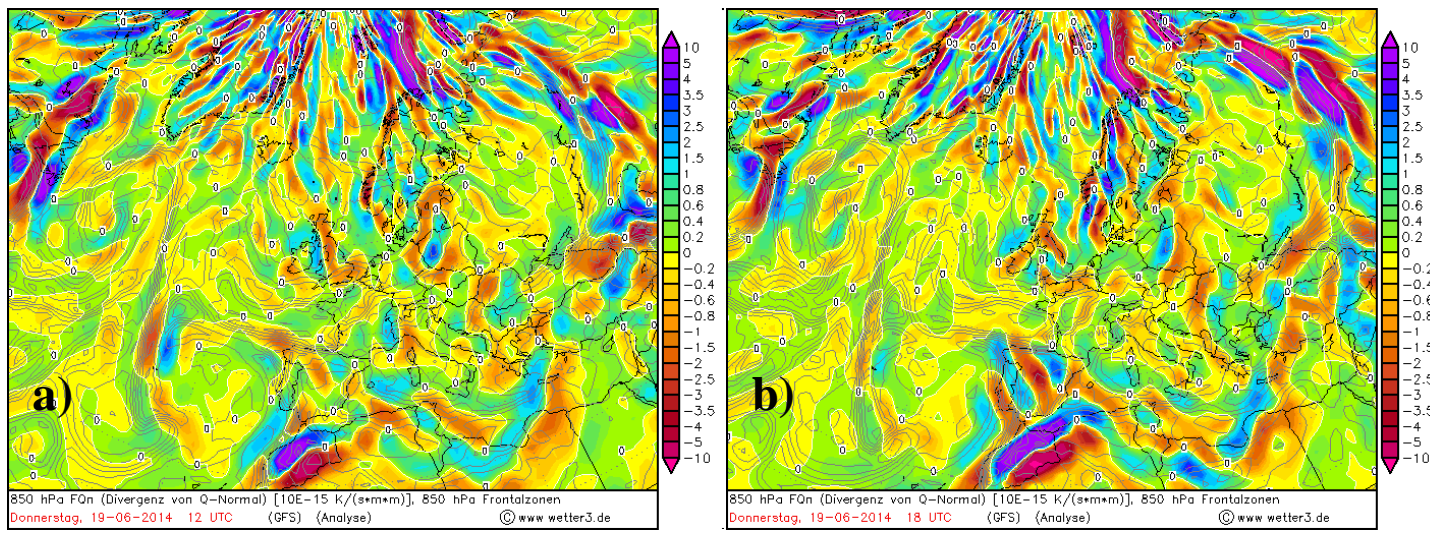

supported the frontal zone passing.
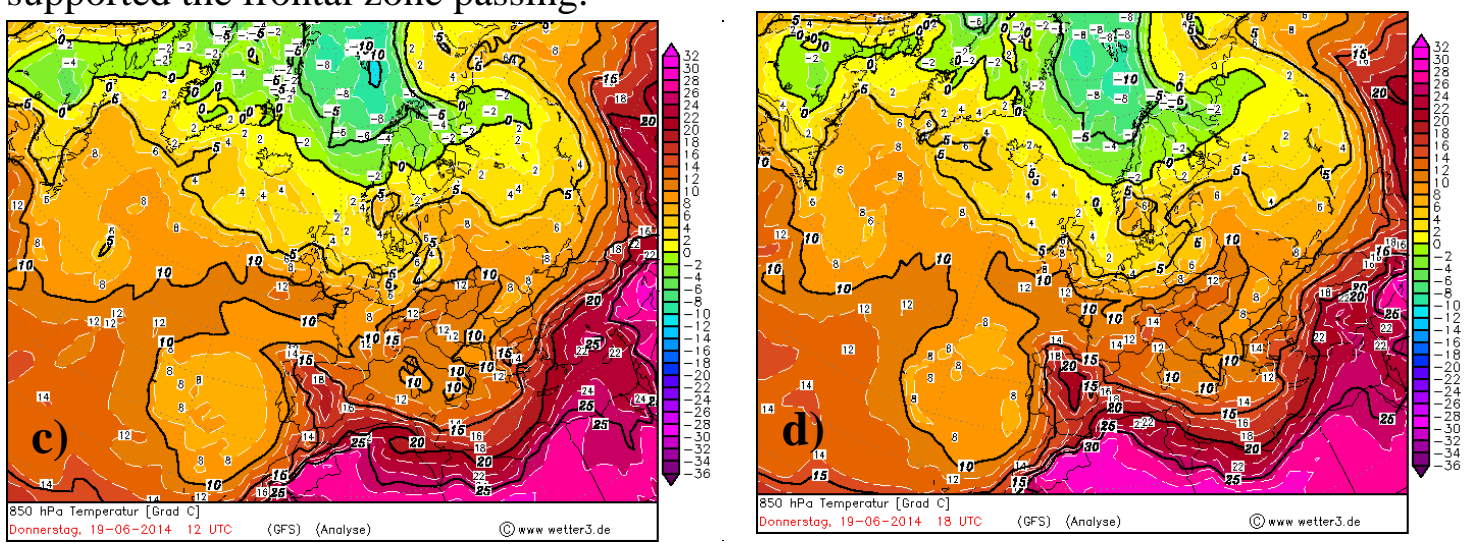

Figure 3: $850 \mathrm{mb}$ frontal zone at a)12:00UTC b)18:00UTC; $850 \mathrm{mb}$ temperature at c) 12:00UTC d) 18:00UTC 
Total precipitation charts showed that before tornado hit (Fig. 4a) precipitation caused from the low pressure system west of Tuzla was seen. After tornado dissipation (Fig. 4b) total precipitation rate was between 0.2 and $5 \mathrm{~mm}$ in 6 hours. These maps are derived in every 6 hours so that the mature phase of tornado can not be identified easily. Thus, WRFARW simulations outputs were obtained for every one hour.

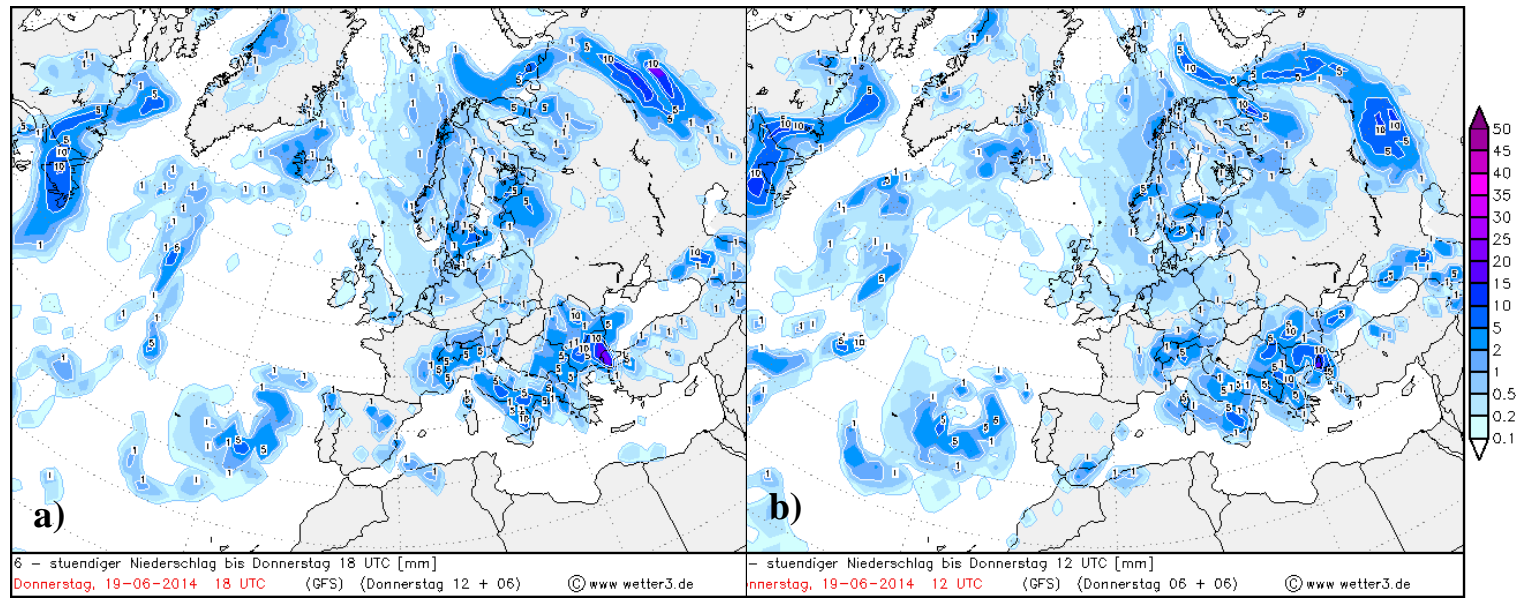

Figure 4: 6-hour total precipitation $(\mathrm{mm})$ a) 12:00UTC b) 18:00UTC.

WRF-ARW 1-hour outputs for June 19, showing direction and magnitude of wind just before the tornado occurrence (Fig. 5a) and while tornado had been dissipating (Fig. 5b), indicated that there was a low pressure system moving to the east where tornado appeared, and northerly winds moving cold air to there. Thus, surface temperatures began to decrease gradually. Wind directions were also examined by using data of Kocaeli meteorological observation station closer to tornado case happened. While looking at the wind directions while tornado had been occurring, maturing and dissipating, significant direction and magnitude changes are noticeable (Fig. 6). According to measured data, before tornado case (Fig. 6a) strong northerly winds were dominated. This situation had prepared the ground for the formation of tornado with the aid of deep low pressure system on the area. While tornado had been observing, winds were measured as variable, but still northern winds were dominant, and with lower magnitude (Fig. 6b). After tornado had dissipated, wind directions were recorded as variant and even lower (Fig. 6c). 


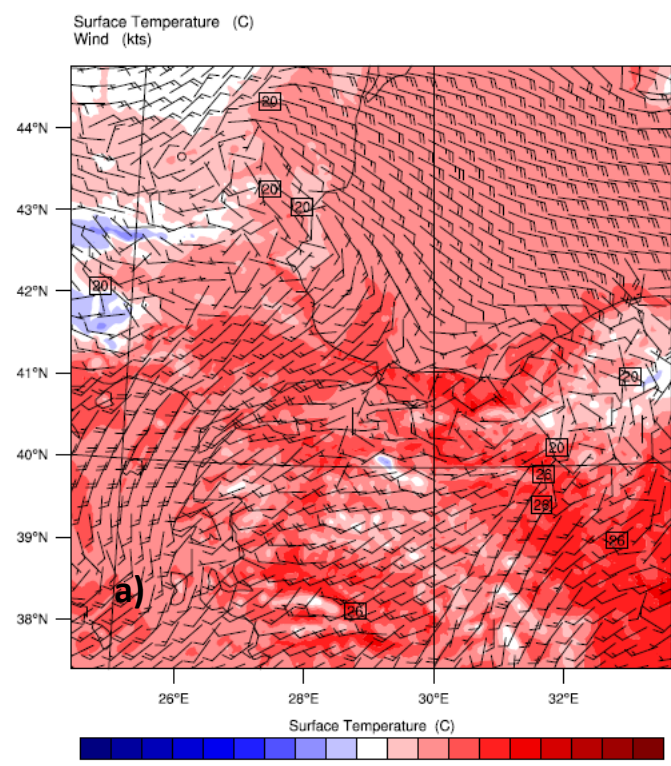

$\begin{array}{llllllllllllllllll}-10 & -7 & -4 & -1 & 2 & 5 & 8 & 11 & 14 & 17 & 20 & 23 & 26 & 29 & 32 & 35 & 38 & 40\end{array}$

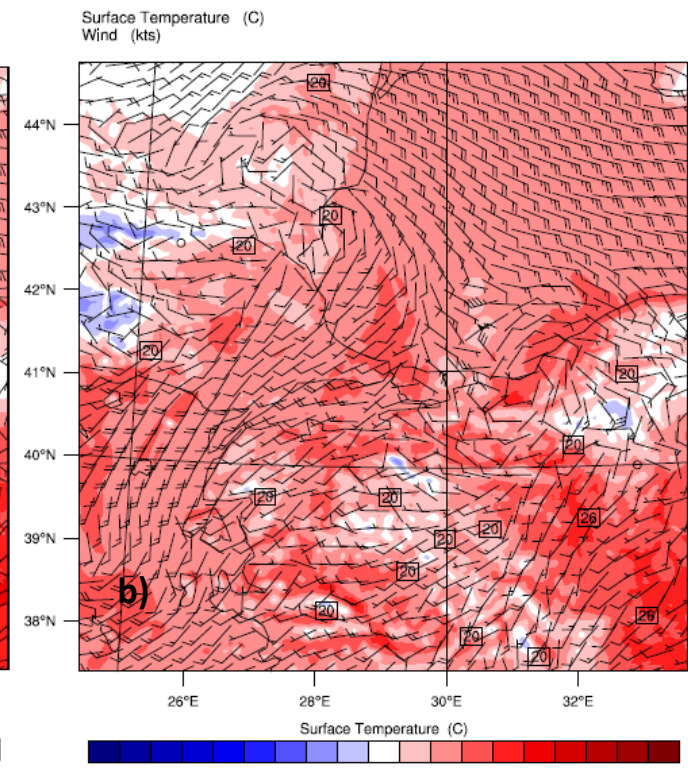

$\begin{array}{llllllllllllllllll}-10 & -7 & -4 & -1 & 2 & 5 & 8 & 11 & 14 & 17 & 20 & 23 & 26 & 29 & 32 & 35 & 38 & 40\end{array}$

Figure 5: 1-hour WRF results that show surface temperature $\left({ }^{\circ} \mathrm{C}\right)$ and winds (kts) a) 15:00UTC b) 16:00UTC.
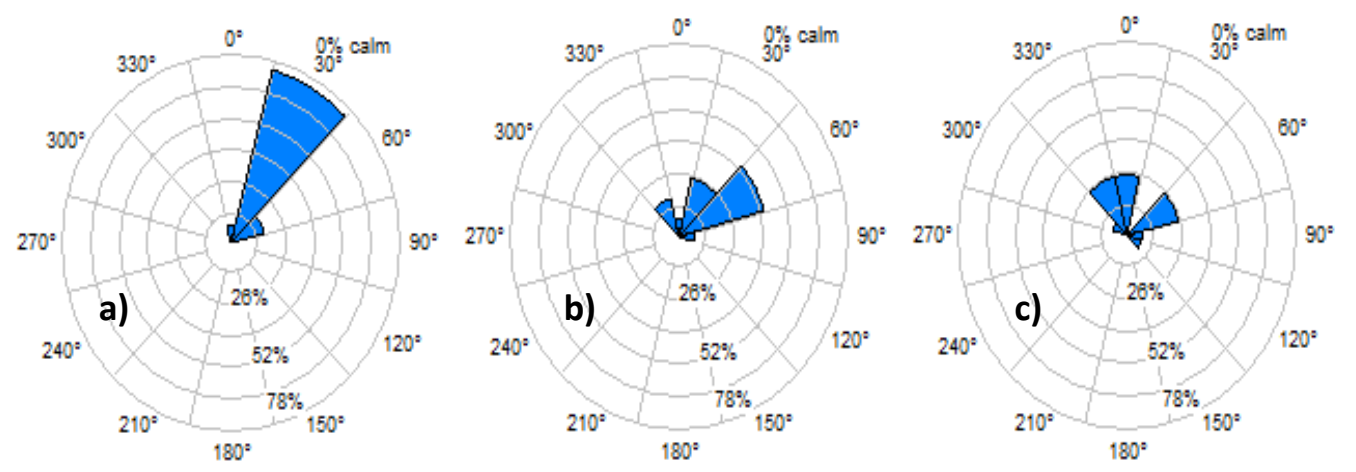

Figure 6: Wind direction between a)12:00-14:00UTC b)14:00-16:00UTC c)16:00-18:00 UTC

WRF-ARW results visualized on coarser domain, also showed that precipitation tendency over the area was nearly $6.5 \mathrm{~mm}$ between 14:00-15:00UTC and the area was under the influence of low pressure system located in the northeast of Turkey on June, 19. The trough of this system (1004 mb isobar on the sea level) was inserted into the area where tornado appeared (Fig. 7a). Total precipitation was between $6.5-12.8 \mathrm{~mm}$ according to 15.00UTC WRF-ARW output (Fig. 7b).

In the Fig. 8, precipitation tendency and total precipitation amounts before and after tornado were given. Especially in the northwest of Turkey, an intensive precipitation area due to low pressure system was exist. While tornado case had been taking place, the intensity of precipitation is more (Fig. 8c) than previous image (Fig. 8a). Real-time satellite and radar images at the same time (18UTC) (Fig. 9) showed the similar results with model predictions. After tornado case, deep low pressure located in the northwest moving to the east standed out. 

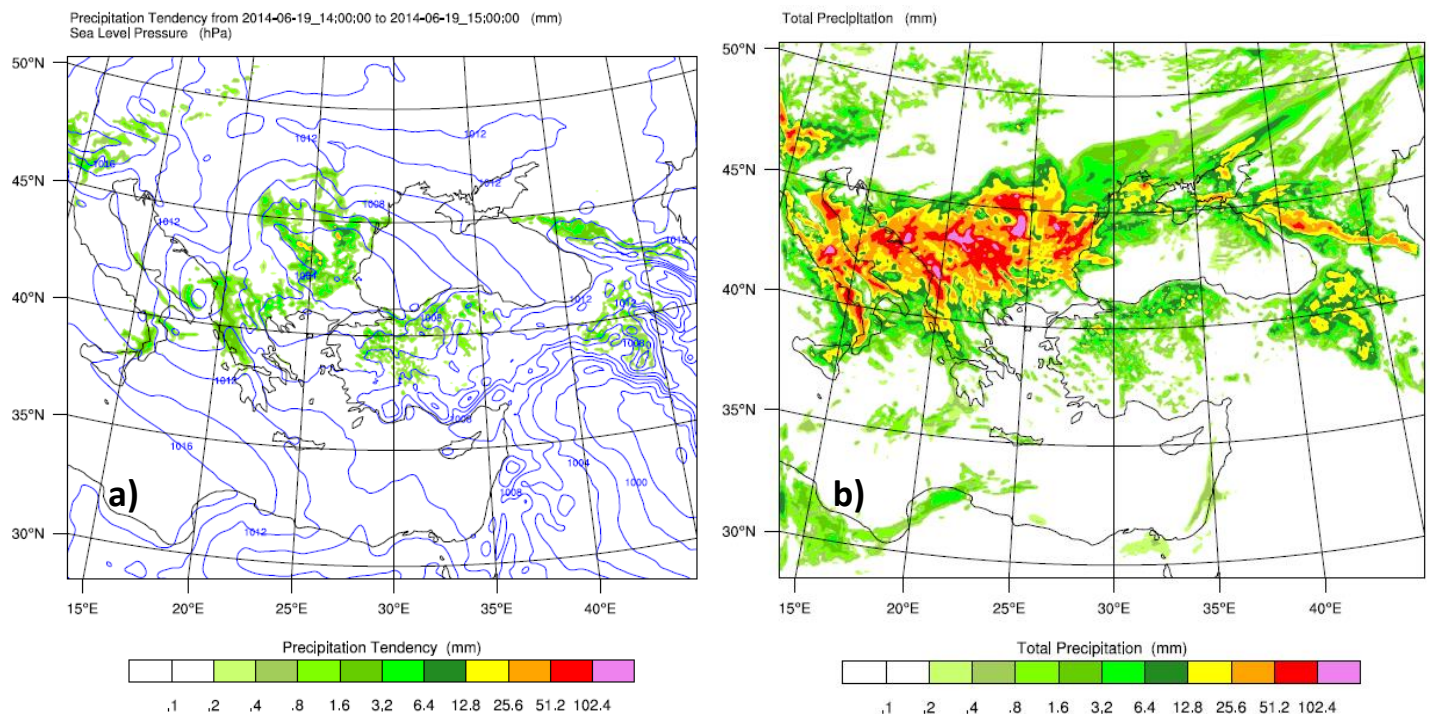

Figure 7: 1-hour WRF results that show a) Precipitation tendency $(\mathrm{mm})$ and sea level pressure $(\mathrm{mb})$ between 14:00UTC-15:00UTC b) Total precipitation $(\mathrm{mm})$ between 14:00UTC-15:00UTC.
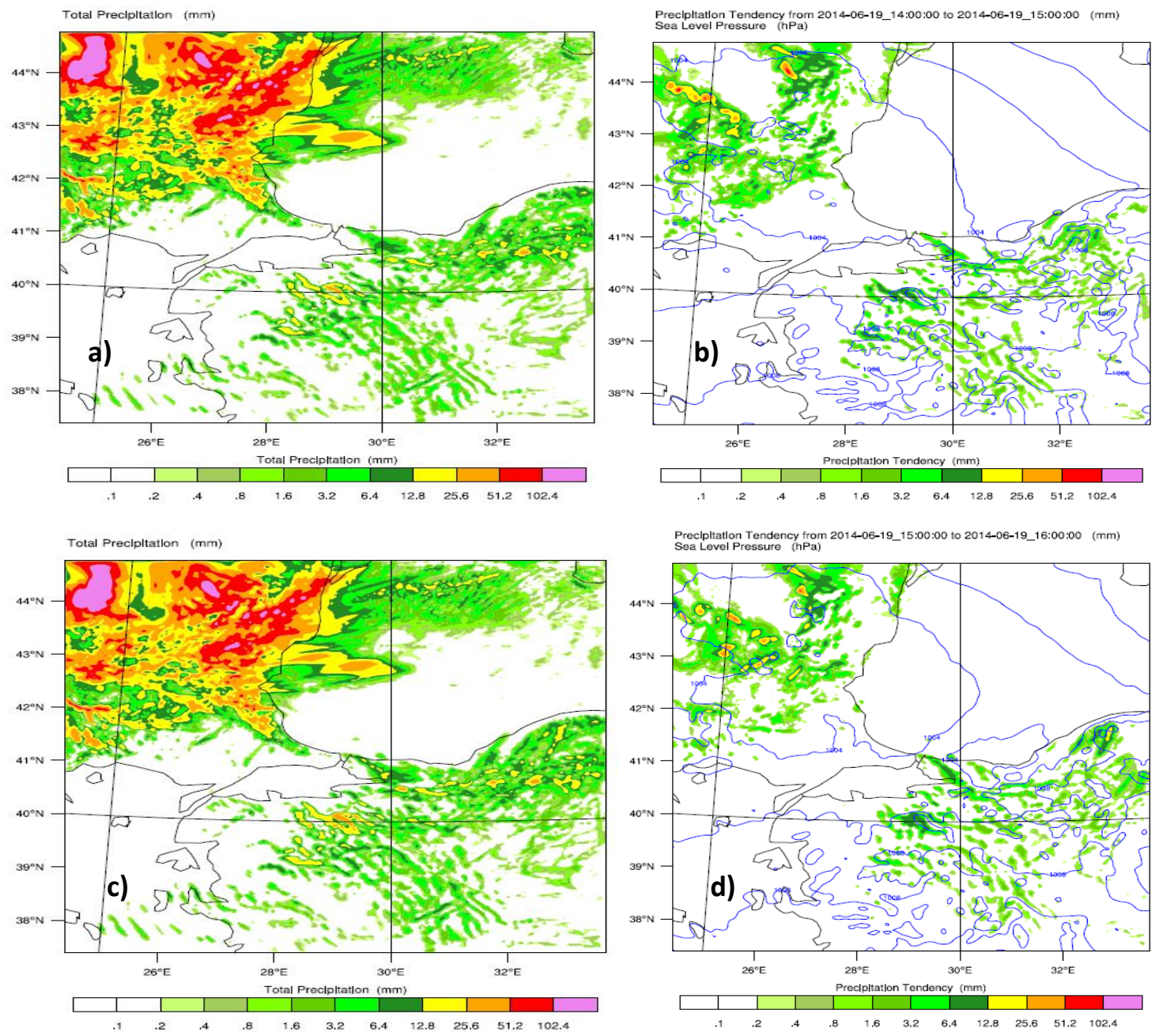

Figure 8: 1-hour WRF results between 14:00UTC-15:00UTC a) Total precipitation b) Precipitation tendency $(\mathrm{mm})$ and sea level pressure $(\mathrm{mb})$, between 15:00UTC-16:00UTC c) Total precipitation d) Precipitation tendency $(\mathrm{mm})$ and sea level pressure $(\mathrm{mb})$ 

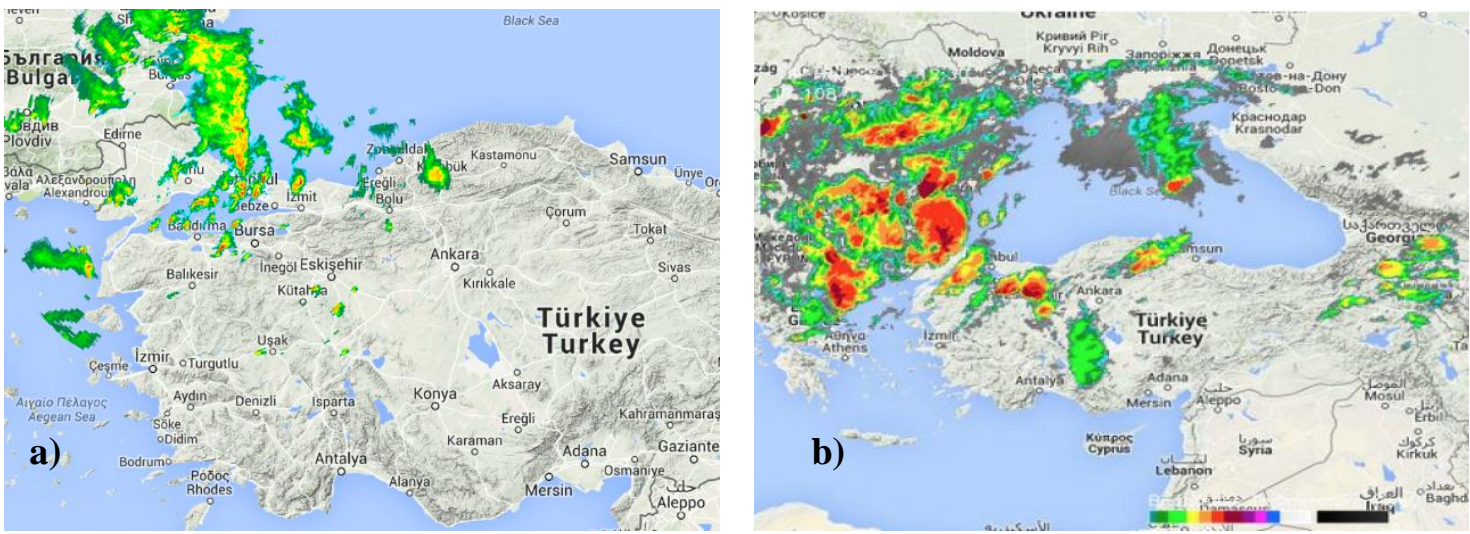

Figure 9: Images of June 19, 2015 a) radar and b) satellite

In order to see the effects of tornado on measured data (pressure, temperature, wind speed and wind direction) taken from two meteorological stations (Pendik and Kocaeli) were examined on the time series graphics.
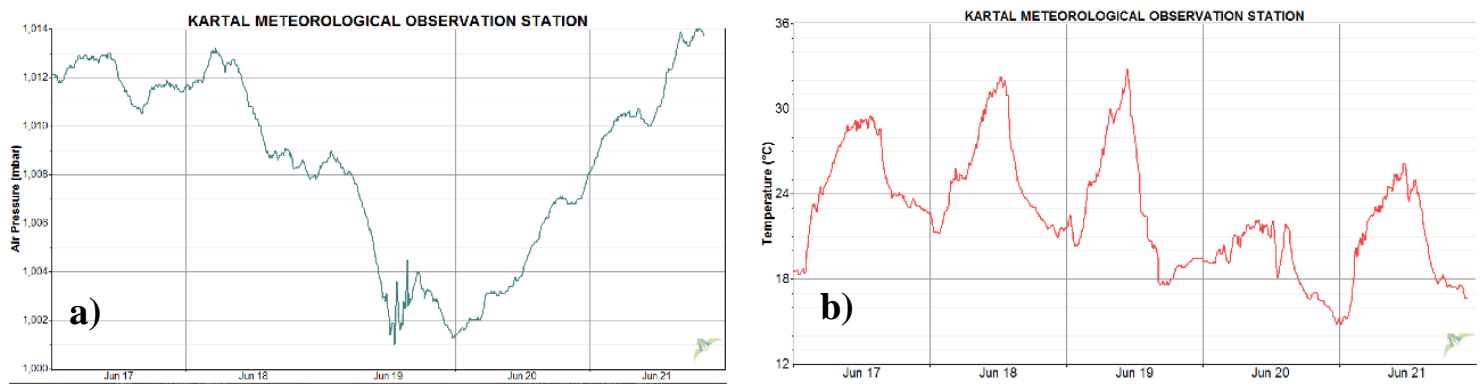

Figure 10: Time series of data from Kartal Meteorological Observation Station

a) pressure $(\mathrm{mb}) \mathrm{b})$ temperature $\left({ }^{\circ} \mathrm{C}\right)$

When tornado case happened (June 19) obvious decrease of pressure and temperature can be realized in Kartal close to Tuzla where tornado hit (Fig. 10). After tornado case due to the cold air mass behind the cold front caused a sharp decrease in temperatures from 34 ${ }^{\circ} \mathrm{C}$ to $18{ }^{\circ} \mathrm{C}$. Formation of a tornado needs a supporter low pressure system so pressure levels began to decrease gradually from 2 days before the case from $1012 \mathrm{mb}$ to $1001 \mathrm{mb}$.
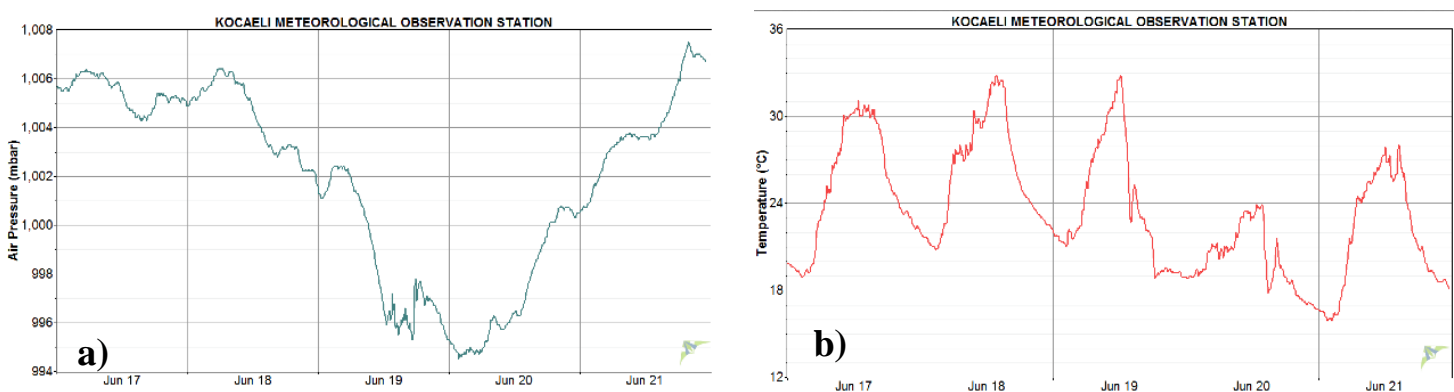

Figure 11: Time series of data from Kocaeli Meteorological Observation Station a) pressure $(\mathrm{mb}) \mathrm{b})$ temperature $\left({ }^{\circ} \mathrm{C}\right)$

For the same day pressure and temperature were decreased clearly also in Kocaeli where closer to Tuzla where tornado hit (Fig. 11). Although decrese in temperature was nearly same as Pendik, decrease in pressure was from $1006 \mathrm{mb}$ to $995 \mathrm{mb}$ from 2 days before the case. Despite of the pressure change in two stations was nearly $11 \mathrm{mb}$, the low level system affected on Kocaeli due to the closenest to the sea shore where tornado was seen. 


\section{RESULTS AND DISCUSSION}

With this case study, a tornado development in June 19, 2015 in Tuzla was examined with WRF-ARW simulation, synoptic charts and measured observation data. According to its damage intensity, tornado was classified as F2 (Fujita scale) and T2 (TORRO scale). 500 and $850 \mathrm{mb}$ upper level charts were interpreted to see the frontal zone passing and temperature changes in the atmosphere. 6-hour total precipitation charts showed that before tornado development the precipitation occurred in the western part of Tuzla then when the storm move to the direction of Black Sea, tornado get more intensive and the total precipitation was observed between 0.2 and $5 \mathrm{~mm}$. According to WRF-ARW predictions, these values reached 6.5 to $12 \mathrm{~mm}$. WRF-ARW predicted the location and movement of low pressure system correctly but intensity of precipitation was overestimated.

While real time wind direction data belonging to Kocaeli meteorological observation station on June 19 and WRF-ARW predictions were compared, variation of the winds were predicted accurately in the model. During the tornado case, strong northerly winds were dominated. Just after tornado had dissipated, the winds became variant with less magnitude than before.

According to the observation data, decrase of pressure and temperature were noticeable at Pendik and Kocaeli stations which were close to tornado hit area.

During tornado case, deep low pressure system was conspicuous both in WRF-ARW results and radar and satellite images. This situation caused intensive precipitation in the area.

As a result, there were suitable circumstances for tornado formation on June 19, 2015 such as decreasing of pressure and temperature, strong winds and existence of moisture source like Black Sea. These all factors supported the development of tornado and damage of tornado was inevitable due to its appearance is rare in Turkey's coastlines.

\section{REFERENCES}

[1] Url-1 < http://www.spc.noaa.gov/faq/tornado/f-scale.html. Retrieved date: 10.01 .2015

[2] I. T. Matsangouras, P. T. Nastos, and I. Pytharoulis. Synoptic-mesoscale analysis and numerical modeling of a tornado event on 12 February 2010 in northern Greece, Advances in Science \& Research, vol.6, pp 187-194, 2011.

[3] A. J. Litta, U. C. Mohanty S, Kiran Prasad, M. Mohapatra, Ajit Tyagi, S. C. Sahu. Simulation of tornado over Orissa (India) on March 31, 2009, using WRF-NMM model, Natural Hazards, vol. 61, pp 1219-1242, 2012.

[4] Fatima Akter, Hirohiko Ishikawa. Synoptic features and environmental conditions of the tornado outbreak on March 22, 2013 at Brahmanbaria in the east-central region of Bangladesh, Natural Hazards, vol. 74, pp 1309-1326, 2014. 